\title{
Inappropriate gestational weight gain among teenage pregnancies: prevalence and pregnancy outcomes
}

\section{Yada Vivatkusol}

Thaovalai Thavaramara

Chadakarn Phaloprakarn

Department of Obstetrics and Gynecology, Faculty of Medicine Vajira Hospital, Navamindradhiraj University, Bangkok, Thailand
Correspondence: Thaovalai Thavaramara Department of Obstetrics and Gynecology, Faculty of Medicine Vajira Hospital, Navamindradhiraj University, 68I Samsen Road, Dusit District,

Bangkok 10300, Thailand

Tel +66 22443405

Fax +66 22437907

Email thaovalai@nmu.ac.th
This article was published in the following Dove Press journal:

International Journal of Women's Health

17 May 2017

Number of times this article has been viewed

Objective: To study the prevalence and pregnancy outcomes of inappropriate gestational weight gain (GWG) among teenage pregnant women.

Methods: A retrospective descriptive study was conducted on 2,165 teenage pregnant women who attended our antenatal clinic between January 2007 and August 2015. Adverse pregnancy outcomes, including maternal and neonatal outcomes of women with inappropriate GWG, including underweight and overweight, were studied and compared with those of women with appropriate GWG.

Results: Complete data of 1,943 women were obtained. Among these women, the mean age was $17.4 \pm 1.4$ years and mean body mass index at first visit was $19.1 \pm 3.0 \mathrm{~kg} / \mathrm{m}^{2}$. The prevalence of inappropriate GWG was $61.7 \%$. Underweight women were more likely to experience anemia and preterm delivery, whereas overweight women required more cesarean sections because of cephalopelvic disproportion and preeclampsia, compared to women with appropriate weight gain (all $P<0.001$ ). The rates of gestational diabetes mellitus among women who were underweight, overweight, or appropriate weight were not significantly different.

Conclusion: More than $60 \%$ of teenage pregnancies showed inappropriate GWG. GWG had a significant impact on pregnancy outcomes.

Keywords: prevalence, pregnancy outcome, inappropriate gestational weight gain, teenage pregnancy

\section{Introduction}

About 16 million girls aged 15-19 years, and about 1 million $<15$ years, give birth every year, mostly in low- and middle-income countries. ${ }^{1}$ The definition of teenage pregnancy by the World Health Organization is a pregnant woman aged between 15 and 19 years. ${ }^{2}$ In Thailand, the data show a high rate of teenage pregnancy, and the birth rate among teenage girls was $42.2 \%$ in 1990 and $53.8 \%$ in 2012 . The fertility proportion in teenage pregnant women aged between 10 and 14 years was 0.2 in 1990 and 0.5 in 2012. ${ }^{3}$ The data show a tendency toward decreasing age in teenage pregnant women.

Complications during pregnancy and childbirth are the second cause of death for 15-19-year-old girls globally. Every year, some 3 million girls aged 15-19 years undergo unsafe abortions. Babies born from adolescent mothers face a substantially higher risk of mortality than those born to women aged 20-24 years. Compared with pregnant adults, teenage pregnancy increases complications in pregnancy, such as preeclampsia, preterm labor, and fetal complications such as low birth weight. ${ }^{4-6}$ Data from the ministry of Public Health of Thailand in 2006 found that the rate of neonatal low birth weight in teenage pregnancy was $13.4 \%$, compared with $8.3 \%$ in pregnant 
adults. $^{7}$ Teenage pregnancies experienced more complications than adult pregnancies from incomplete development of pelvic organs and preterm birth, ${ }^{8}$ as well as respiratory complications, such as fetal respiratory distress syndrome. ${ }^{9}$

Most teenage pregnancies are unplanned, and suffer more prepregnancy health problems because of poor education. As a result, this can lead to inappropriate weight gain and affect the fetus. Some data show that maternal weight gain affects fetal birth weight. Underweight pregnant women, or those with poor weight gain, had an increased risk of preterm birth, and low-birth weight infants. ${ }^{10}$ On the other hand, overweight pregnant women, and those with excessive weight gain, were at increased risk of pregnancy-induced hypertension (PIH), gestational diabetes mellitus, macrosomia, birthcanal tear from difficult labor, and an increased rate of cesarean section. ${ }^{10,11}$ The promotion of appropriate weight gain in teenage pregnancy between antenatal care (ANC), following Institute of Medicine (IOM) guidelines, may decrease these complications. ${ }^{12}$

Thai women are different from other ethnicities. There is no previous data about body mass index (BMI) and weight gain in pregnant Thai teenagers. The prevalence of pregnancy, BMI, weight gain, and pregnancy outcomes should be explored in pregnant Thai teenagers. The aim of this study was to determine the prevalence of appropriate and inappropriate weight gain in four categories. A further aim was to evaluate outcomes of appropriate and inappropriate weight gain.

\section{Materials and methods}

This descriptive study was conducted by reviewing medical records of pregnant women who presented for ANC and delivered in our institute between January 2007 and August 2015. Eligibility criteria were pregnant teenage women, with singleton pregnancy who had attended at least four ANC sessions. These women had to have a certain gestational age (GA) by their last menstrual period, or by early ultrasound at an initial visit. Exclusion criteria were women who had medical disorders or any condition that may affect pregnancy outcomes (eg, preexisting diabetes, chronic hypertension, autoimmune disease, renal disease, and so on), severe congenital and/or chromosomal abnormality, incomplete data record, and non-Thai ethnicity. The study was approved by the Vajira Institutional Review Board (Registered Number 036/58). The Vajira Institutional Review Board did not require patient consent because patients' names were not included when data were collected.

We divided the study population into four categories according to IOM guidelines. The underweight group was pregnant women whose prepregnancy BMI was $<18.5 \mathrm{~kg} / \mathrm{m}^{2}$. The normal weight group was pregnant women whose prepregnancy BMI was between 18.5 and $24.9 \mathrm{~kg} / \mathrm{m}^{2}$. The overweight group was pregnant women whose prepregnancy BMI was between 25 and $29.9 \mathrm{~kg} / \mathrm{m}^{2}$. The obesity group was pregnant women whose prepregnancy BMI was over $30 \mathrm{~kg} / \mathrm{m}^{2}$. We then categorized the appropriate and inappropriate weight gain according to IOM guidelines. Appropriate weight gains in the underweight group, normal weight group, overweight group, and obese group were 13-18, 11-16, 7-11, and 5-9 kg, respectively. ${ }^{11}$ Inappropriate underweight gains were $<13$, $<11,<7$, and $<5 \mathrm{~kg}$, respectively. ${ }^{11}$ Inappropriate overweight gains were $>18,>16,>11$, and $>9 \mathrm{~kg}$, respectively. ${ }^{11}$

Sample size was calculated based on our pilot study, which found that the prevalence of inadequate or inappropriate weight gain in underweight, normal weight, overweight, and obese women was $24.3 \%, 28.2 \%, 3.9 \%$, and $2.9 \%$, respectively. Using this information along with a $5 \%$ chance of making a type I error with a maximum allowable error of $5 \%$, the total number of women needed was at least 1,880 .

Data collection included maternal demographic and antenatal characteristics, delivery information, and adverse pregnancy outcomes. BMI was calculated from self-reported prepregnancy weight $(\mathrm{kg})$ divided by height squared $\left(\mathrm{m}^{2}\right)$. Gestational weight gain during pregnancy was defined as the weight measured on the date of admission to the delivery ward minus prepregnancy weight. Weight measurements of all women were performed using the same weighing scales at the antenatal clinic and delivery room.

Adverse pregnancy outcomes were divided into maternal and fetal outcomes. Adverse maternal outcomes were $\mathrm{PIH}$, gestational diabetes mellitus, cesarean section due to cephalopelvic disproportion, and operative vaginal delivery. PIH was defined as systolic blood pressure exceeding $140 \mathrm{mmHg}$ or diastolic blood pressure exceeding $90 \mathrm{mmHg}$ beyond 20 weeks GA. Gestational diabetes mellitus was defined as glucose intolerance of variable degree with onset or first recognition during pregnancy. Adverse fetal outcomes included low birth weight, birth asphyxia, and neonatal intensive care unit (NICU) admission. Low birth weight referred to neonatal birth weight $<2,500 \mathrm{~g}$. Birth asphyxia was defined as 5 minute Apgar score below 7. The criteria for NICU admission in our institution were respiratory or circulatory instability, suspected sepsis, and the need for close observation as assessed by the attending neonatologist.

The data were analyzed by SPSS version 22 (IBM). Chisquare test and Fisher's exact test were used for categorical data, and Student's $t$-test was used for continuous data. 
The possible factors identified with multivariate analysis were further entered into the logistic regression analysis to determine independent patient predictors and presented as odds ratio (adjusted odds ratio) and 95\% confidence interval. $P$-value of $<0.05$ was considered statistically significant.

\section{Results}

The mean maternal age was $17.4 \pm 1.4$ years and the average number of ANC visits was $8.4 \pm 2.7$ times. Most maternal education was secondary. Most mothers were nulliparous $(86.8 \%)$. Weight gain in the four categories of teenage pregnancy was mostly inappropriate $(61.7 \%)$. The most common route of delivery was normal delivery. Percentage of cesarean section was increased in the overweight and obese subgroups; in contrast, the rate of preterm births showed an increase in underweight subgroup.

A total of 2,165 teenage pregnant women were included in this study. Of these, 222 were excluded due to incomplete data. A total of 1,943 teenage pregnant women were enrolled whose data we were able to analyze. Demographic and antenatal characteristics of pregnant women in the study are presented in Table 1.

The prevalence of BMI that showed either underweight, normal weight, overweight, or obesity prepregnancy was 723 of 1,943 (37.2\%), 1,047 of 1,943 (53.9\%), 120 of 1,943 $(6.2 \%)$, and 53 of $1,943(2.7 \%)$, respectively.

The prevalence of weight gain in four IOM categories is shown in Table 2.
The studied women were divided into three subgroups based on their weight gains: appropriate weight gain, inappropriate underweight gain, and inappropriate overweight gain groups. Their demographic data are summarized in Table 3.

In the underweight gain subgroup, anemia was significant on initial laboratory tests, and in the third trimester $(P<0.001)$. Preterm birth was significant in the underweight gain subgroup $(P<0.001)$. Gestational diabetes mellitus occurred in the underweight gain subgroup than in other groups with no significance $(P=0.119)$. PIH was significant in overweight gain subgroup $(P<0.001)$. Cephalopelvic disproportion was significant in the overweight gain subgroup $(P<0.001)$. Fetal birth asphyxia was significant in the underweight gain subgroup $(P=0.016)$. Most birth asphyxia were due to preterm birth $(P=0.016)$. Fetal low birth weight was significant in underweight gain subgroup $(P<0.001$; Table 4).

\section{Discussion}

Previous data showed that a high proportion of pregnant teenagers had an underweight BMI because of several factors, such as unplanned pregnancy, kept secret from parents, a tendency to being skinny, and malnutrition. For those reasons, this specific group of women required adequate nutrition. Previous data showed that they should focus on food, rather than specific nutrients, because they tended to think concretely. ${ }^{13}$ But the present study showed that the prevalence of teenage pregnancy, according to prepregnancy

Table I Demographic, gravida, delivery mode, and birth data for pregnant teenagers shown by Institute of Medicine weight categories

\begin{tabular}{|c|c|c|c|c|c|}
\hline & Underweight ( $n=723)$ & Normal weight $(n=I, 047)$ & Overweight $(n=\mid 20)$ & Obesity $(n=53)$ & Overall $(n=I, 943)$ \\
\hline Mean age $( \pm S D)$, years & $17.3( \pm I .4)$ & $17.4( \pm 1.4)$ & $17.9( \pm 1.3)$ & $17.8( \pm 1.3)$ & $17.4( \pm I .4)$ \\
\hline \multicolumn{6}{|l|}{ Education, $\mathrm{n}(\%)$} \\
\hline Primary & $108(38.6)$ & $\mid 45(5 \mid .8)$ & $15(5.3)$ & $12(4.3)$ & $280(100.0)$ \\
\hline Middle school & $391(36.1)$ & $592(55.7)$ & $68(6.3)$ & $31(2.9)$ & I,082 (100.0) \\
\hline Senior high school & $204(37.8)$ & $291(53.9)$ & $35(6.5)$ & $10(1.8)$ & $540(100.0)$ \\
\hline Undergraduate & $20(48.8)$ & $19(46.3)$ & $2(4.9)$ & $0(0)$ & $4 I(100.0)$ \\
\hline \multicolumn{6}{|l|}{ Gravida, n (\%) } \\
\hline Nulliparous & $631(37.4)$ & $911(54.0)$ & $102(6.0)$ & $44(2.6)$ & $688(100.0)$ \\
\hline Multiparous & $92(36.1)$ & $136(53.3)$ & $18(7.1)$ & $9(3.5)$ & $255(100.0)$ \\
\hline \multicolumn{6}{|c|}{ Mode of delivery, $n(\%)$} \\
\hline Vaginal delivery & $613(39.2)$ & $840(53.7)$ & $78(5.0)$ & $32(2.1)$ & I,563 (100.0) \\
\hline Normal labor & $582(39.1)$ & $809(54.4)$ & $69(4.6)$ & $28(1.9)$ & I,488 (100.0) \\
\hline Vacuum extraction & $27(40.9)$ & $28(42.4)$ & $8(12.1)$ & $3(4.5 \%)$ & $66(100.0)$ \\
\hline Forcep extraction & $4(44.5)$ & $3(33.3)$ & I (II.I) & I (II.I) & $9(100.0)$ \\
\hline Cesarean section & $110(28.9)$ & $207(54.5)$ & $42(11.1)$ & $21(5.5)$ & $380(100.0)$ \\
\hline \multicolumn{6}{|l|}{ Birth, n (\%) } \\
\hline Term & $646(36.4)$ & $966(54.4)$ & $114(6.4)$ & $51(2.8)$ & I,777 (100.0) \\
\hline Preterm & $77(46.4)$ & $81(48.8)$ & $6(3.6)$ & $2(1.2)$ & $166(100.0)$ \\
\hline
\end{tabular}

Abbreviation: SD, standard deviation. 
Table 2 Prevalence of weight gain based on prepregnancy BMI and shown by Institute of Medicine weight gain categories

\begin{tabular}{llllll}
\hline Weight gain & Underweight $(\mathbf{n}=\mathbf{7 2 3})$ & Normal weight $(\mathbf{n}=\mathbf{I}, \mathbf{0 4 7})$ & Overweight $(\mathbf{n}=\mathbf{I} \mathbf{2 0})$ & Obesity $(\mathbf{n}=\mathbf{5 3})$ & Overall $(\mathbf{n}=\mathbf{I , 9 4 3})$ \\
\hline Appropriate, $\mathrm{n}(\%)$ & $284(38.2)$ & $426(57.3)$ & $27(3.6)$ & $7(0.9)$ & $744(I 00.0)$ \\
Inappropriate, $\mathrm{n}(\%)$ & & & & & \\
$\quad$ Underweight gain & $302(47.2)$ & $320(50.0)$ & $13(2.0)$ & $5(0.8)$ & $640(100.0)$ \\
Overweight gain & $137(24.5)$ & $30 I(53.8)$ & $80(14.3)$ & $4 I(7.4)$ & $559(100.0)$ \\
\hline
\end{tabular}

Abbreviation: BMI, body mass index.

BMI categories, was $53.9 \%, 37.2 \%, 6.2 \%$, and $2.7 \%$ for normal weight, underweight, overweight, and obesity, respectively. Our findings differed from the results of a previous study conducted in the USA, which showed a higher prevalence of obesity but a lower prevalence of underweight (ie, $58.6 \%, 3.17 \%, 16.9 \%$, and $21.3 \%$ for normal weight, underweight, overweight, and obesity, respectively). ${ }^{14}$ This might be because our teenage population had lesser-quality ANC resulting in poorer self-care. Another previous study showed that most teenage pregnancies were underweight gain because of poor nutrition and concern for their shape before and during the course of pregnancy so they needed more nutrition. ${ }^{13}$ Similar to our findings, a previous study in the USA showed that the most common prepregnancy BMI was normal weight. The second most common prepregnancy BMI in such a study was obesity, which contrasted with our finding of underweight.

Concerning weight gain, our study and a previous study from the USA and Canada, ${ }^{14,15}$ found that a majority of teenage mothers had inappropriate weight gain, especially overweight gain, which was commonly observed in western countries. ${ }^{16,17}$ In contrast, the underweight and normal weight groups showed below-average weight gain, but the overweight and obesity groups showed above-average weight gain. The likely explanation for these discrepancies might be due to differences in nutritional behavior, lifestyle, and social and cultural aspects.

Our study showed that the overall rate of overweight gain in teenage pregnancy was $28.8 \%(559 / 1,943)$. When we explored each prepregnancy BMI category, we found that rates of overweight gain were markedly higher in overweight and obesity prepregnancy BMI categories: $66.7 \%$ and $77.4 \%$, respectively. These data showed that obese women had a tendency to have excessive weight gain. On the other hand, we found that most of the women in the underweight prepregnancy BMI category had poor weight gain (41.8\%). This trend may occur due to nutritional status and education of pregnant women as underweight women had inadequate nutrition, whereas obese women had excessive intake.

With respect to pregnancy outcomes, our results showed that the rate of preterm births increased from $7.7 \%$ in the appropriate weight gain subgroup to $11.9 \%$ in the underweight gain subgroup. This might be explained by maternal nutritional status as evidence suggests that dietary patterns have an impact on gestational length. ${ }^{18}$ Similarly, we observed higher rates of anemia in the underweight gain subgroup. Nevertheless, this might be overestimated because we included women with thalassemia trait. In contrast, our observed prevalence

Table 3 Demographic, gravida, and delivery mode data for pregnant teenagers shown by weight gain groups

\begin{tabular}{|c|c|c|c|c|}
\hline & $\begin{array}{l}\text { Underweight gain } \\
(n=640)\end{array}$ & $\begin{array}{l}\text { Appropriate weight gain } \\
(n=744)\end{array}$ & $\begin{array}{l}\text { Overweight gain } \\
(n=559)\end{array}$ & $P$-value \\
\hline Mean age $( \pm S D)$, years & $17.3( \pm I .4)$ & $17.5( \pm \mathrm{I} .4)$ & $17.5( \pm I .4)$ & 0.599 \\
\hline Education, $\mathrm{n}(\%)$ & & & & 0.141 \\
\hline Primary & $97(15.2)$ & $99(13.3)$ & $84(15.1)$ & \\
\hline Middle school & $366(57.2)$ & $395(53.1)$ & $321(57.1)$ & \\
\hline Senior high school & $161(25.2)$ & $234(31.5)$ & $144(25.8)$ & \\
\hline Undergraduate & $16(2.5)$ & $16(2.2)$ & $9(1.6)$ & \\
\hline Gravida, n (\%) & & & & 0.034 \\
\hline Nulliparous & $550(85.9)$ & $635(85.3)$ & $503(90.9)$ & \\
\hline Multiparous & $90(14.1)$ & $109(14.7)$ & $56(10.0)$ & \\
\hline Mode of delivery, n (\%) & & & & $<0.001$ \\
\hline \multicolumn{5}{|l|}{ Vaginal delivery } \\
\hline Normal labor & $524(81.9)$ & $597(80.2)$ & $367(65.7)$ & \\
\hline Vacuum extraction & $16(2.5)$ & $21(2.8)$ & $29(5.2)$ & \\
\hline Forcep extraction & $4(0.6)$ & $2(0.3)$ & $3(0.5)$ & \\
\hline Cesarean section & $96(15.0)$ & $124(16.7)$ & $160(28.6)$ & \\
\hline
\end{tabular}


Table 4 Pregnancy outcomes among women with appropriate weight gain and inappropriate under- and overweight gains

\begin{tabular}{|c|c|c|c|c|}
\hline Pregnancy outcome & Underweight gain $(n=640)$ & Appropriate weight gain $(n=744)$ & Overweight gain $(n=559)$ & $P$-value \\
\hline Anemia in first visit & $284(44.4 \%)$ & $290(39.0 \%)$ & $176(31.5 \%)$ & $<0.001$ \\
\hline Anemia in third trimester & $278(43.4 \%)$ & $280(37.6 \%)$ & $169(30.2 \%)$ & $<0.001$ \\
\hline $\begin{array}{l}\text { Caesarean section due to } \\
\text { cephalopelvic disproportion }\end{array}$ & $32(5.0 \%)$ & $67(9.0 \%)$ & 97 (I7.4\%) & $<0.001$ \\
\hline Preeclampsia & $3(0.5 \%)$ & $8(1.1 \%)$ & $24(4.3 \%)$ & $<0.001$ \\
\hline Gestational diabetes mellitus & $6(0.9 \%)$ & I (0.1\%) & $4(0.7 \%)$ & 0.119 \\
\hline Preterm & $76(11.9 \%)$ & 57 (7.7\%) & $33(5.9 \%)$ & $<0.001$ \\
\hline
\end{tabular}

of anemia at the third trimester might be underestimated when compared to the general teenager population, because the women we included had good ANC and received iron supplementation before undergoing blood tests.

MacSween et al observed a significantly increased risk of having a cesarean section in Canadian teenage mothers with overweight gain. ${ }^{19}$ In line with the study of MacSween et al, the highest prevalence (17.4\%) of cephalopelvic disproportion was found in our overweight gain subgroup. These data suggested that the rate of cesarean section increased in women with overweight gain, which was probably because of macrosomia or soft tissue dystocia. Our result was consistent with a previous study conducted in the Middle East, which showed that the rate of cesarean section in teenage pregnancy was $20 \%$ and was slightly higher than the $13.4 \%$ rate found in adult pregnant women. ${ }^{20}$ The cesarean section rate increased in overweight (35\%) and obese $(39.6 \%)$ pregnant mothers. Our data showed that most teenage pregnant women had inappropriate weight gain, especially in overweight and obese pregnant women.

In this study, PIH significantly increased in the overweight gain subgroup. This was similar to the result from a previous study, which found a higher incidence of PIH in the overweight gain group $(P<0.05) .{ }^{21}$

To our knowledge, this is the first study to evaluate pregnancy outcomes by weight gain among four prepregnancy BMI categories of pregnant Asian teenagers. As this was a retrospective study, some data were unavailable, for example, nutrition, lifestyle, and baseline hematocrit. In addition, our data might not be applicable to other teenaged populations who have poor ANC. Further research is required to confirm our results in different groups of teenage pregnant women with inadequate antenatal visits and unplanned delivery.

In conclusion, the prevalence of inappropriate GWG among teenage women was over $60 \%$. Inappropriate gestational weight gain had a significant impact on pregnancy outcomes.

\section{Disclosure}

The authors report no conflicts of interest in this work.

\section{References}

1. Chandra-Mouli V, Camacho AV, Michaud PA. WHO guidelines on preventing early pregnancy and poor reproductive outcomes among adolescents in developing countries. J Adolesc Health. 2013;52(5): 517-522.

2. WHO. WHO Guidelines for Preventing Early Pregnancy and Poor Reproductive Outcomes in Adolescents in Developing Countries. Geneva, Switzerland: WHO; 2011.

3. Sukrat B. Thailand adolescent birth rate: trend and related indicators Thai J Obstet Gynaecol. 2014;22:15-21.

4. Thaithate S, Thato R. Obstetric and perinatal outcomes of teenage pregnancies in Thailand. Adolesc Pediatr Gynecol. 2011;24(6):342-346.

5. Thato S, Rachukul S, Sopajaree C. Obstetrics and perinatal outcome of Thai pregnant adolescents: a retrospective study. Int J Nurs Stud. 2007;44(7):1158-1164.

6. Rocha RC, de Souza E, Soares EP, Nogueira ES, Chambô Filho A, Guazzelli CA. Prematurity and low birth weight among Brazilian adolescents and young adults. J Pediatr Adolesc Gynecol. 2010;23(3): 142-145.

7. Harper LM, Chang JJ, Macones GA. Adolescent pregnancy and gestational weight gain: do the Institute of Medicine recommendations apply? Am J Obstet Gynecol. 2011;205(2):140. e1-e8.

8. WHO. Issues in Adolescent Health and Development. Geneva, Switzerland: WHO; 2004.

9. Werner EF, Savitz DA, Janevic TM, et al. Mode of delivery and neonatal outcomes in preterm, small-for-gestational-age newborns. Obstet Gynecol. 2012;120(3):560-564.

10. Bhattacharya S, Campbell DM, Liston WA, Bhattacharya S. Effect of body mass index on pregnancy outcomes in nulliparous women delivering singleton babies. BMC Public Health. 2007;7:168.

11. Saereeporncharenkul K. Correlation of BMI to pregnancy outcomes in Thai women delivered in Rajavithi hospital. J Med Assoc Thai. 2011; 94 (Suppl 2):S52-S58.

12. Institute of medicine of the national academies. Weight gain during pregnancy: Reexamining the guidelines. Washington, DC: National Academies Press; 2009.

13. Montgomery KS. Improving nutrition in pregnant adolescents: recommendations for clinical practitioners. J Perinat Educ. 2003;12(2):22-30.

14. Elchert J, Beaudrot M, DeFranco E. Gestational weight gain in adolescent compared with adult pregnancies: an age-specific body mass index approach. J Pediatr. 2015;167(3):579-585. e1-e2.

15. Houde M, Dahdouh EM, Mongrain V, Dubuc E, Francoeur D, Balayla J. The effect of adequate gestational weight gain among adolescents relative to adults of equivalent body mass index and the risk of preterm birth, cesarean delivery, and low birth weight. J Pediatr Adolesc Gynecol. 2015;28(6):502-507.

16. Gaillard R, Welten M, Oddy WH, et al. Associations of maternal prepregnancy body mass index and gestational weight gain with cardiometabolic risk factors in adolescent offspring: a prospective cohort study. BJOG. 2016;123(2):207-216.

17. Aktun LH, Yorgunlar B, Karaca N, Akpak YK. Predictive risk factors in the treatment of gestational diabetes mellitus. Clin Med Insights Womens Health. 2015;8:25-28. 
18. Bloomfield FH. How is maternal nutrition related to preterm birth? Ann Rev Nutr. 2011;31:235-261.

19. MacSween K, Whelan E, Woolcott CG. Gestational weight gain and perinatal outcomes in adolescent mothers: a retrospective cohort study. J Obstet Gynaecol Can. 2016;38(4):338-345.

20. Mohamed AA, Almalaq AA, Almansour RD, Alanazi HS, Al-Khamali MM, Shommo SA. Mode of delivery and birthweight among teenage and adult primigravida Saudi women: a retrospective comparative study. J Obstet Gynaecol Res. 2015;41(11):1721-1725.
21. Yin YZ, Chen XW, Li XM, Hou HY, Zhou SS. [Relations of prepregnant weight and weight gain during pregnancy with pregnancyinduced hypertension and birth weight.] Di Yi Jun Yi Da Xue Xue Bao. 2005;25(2):226-228. Chinese.

International Journal of Women's Health

Dovepress

\section{Publish your work in this journal}

The International Journal of Women's Health is an international, peerreviewed open-access journal publishing original research, reports, editorials, reviews and commentaries on all aspects of women's healthcare including gynecology, obstetrics, and breast cancer. The manuscript management system is completely online and includes a very quick and fair peer-review system, which is all easy to use. Visit http://www.dovepress.com/testimonials.php to read real quotes from published authors.

Submit your manuscript here: http://www.dovepress.com/international-journal-of-womens-health-journal 